\title{
放牧和围封条件下克氏针茅草原土壤种子库的比较
}

\author{
詹学明 1,2 李凌浩 $1 *$ 李 金金 1 程维信 1 \\ （1 中国科学院植物研究所植被数量生态学重点实验室, 北京 100093）（2 中国科学院研究生院, 北京 100039）
}

\begin{abstract}
摘 要 应用幼苗萌发法对比研究了我国北方农牧交错区克氏针茅 (Stipa krylovii) 草原在放牧和围封条件下土壤 种子库的差异。围封样地的土壤种子库中记录有 16 个物种, 其中禾草类 6 种, 非禾草类 10 种; 若以生活型划分, 则 全部为多年生植物; 若以单子叶或双子叶植物划分, 则单子叶植物 9 种, 双子叶植物 7 种。放牧样地的土壤种子库 中记录有 13 个物种, 其中禾草类 4 种, 非禾草类 9 种; 多年生植物 12 种, 一二年生植物 1 种; 单子叶植物 5 种, 双子 叶植物 8 种。放牧样地土壤种子库的密度为 (3 664 \pm 1087 ) 粒 $\cdot \mathrm{m}^{-2}$, 围封样地土壤种子库的密度是 (5 $139 \pm 1848$ ) 粒 $\cdot \mathrm{m}^{-2}$, 差异显著。采用 Sorensen 指数计算土壤种子库与地上植被的物种相似性, 围封样地和放牧样地分别是 0.711 和 0.611 。两个地点的全部种子中, $81.0 \%$ 属于冷蒿 (Artemisia frigida)、克氏针茅、星毛委陵菜 (Potentilla acaulis)、粘隐子草(Cleistogenes squarrosa) 和砂非 (Allium bidentatum) 5 种优势植物, $16.2 \%$ 属于二裂委陵菜 ( $P$. bifur$c a$ )、菊叶委陵菜 ( P. tanacetifolia)、猪毛蒿 $(A$. scoparia )、冰草 (Agropyron cristatum) 和羊草 ( Leymus chinensis $) 5$ 种常见植 物, 而其余 9 种植物的种子数只占 $2.8 \%$ 。此外, 通常作为优良牧草的豆科植物的种子数仅占 $0.6 \%$ 。上述结果表 明, 在放牧条件下由于土壤种子库中一些重要物种的缺失或数量很少以及极不均匀的分布, 可能会降低退化克氏 针茅草原的自然恢复速度。我们建议采取补播这些重要物种并结合其它恢复措施来加快退化克氏针茅草原的恢 复进程。
\end{abstract}

关键词 农牧交错区 退化草原 恢复 相似性

\section{EFFECTS OF GRAZING ON THE SOIL SEED BANK OF A STIPA KRYLOVII STEPPE COMMUNITY}

\author{
ZHAN Xue-Ming $^{1,2}$ LI Ling-Hao ${ }^{1 *}$ LI Xin ${ }^{1}$ and CHENG Wei-Xin ${ }^{1}$ \\ (1 Laboratory of Quantitative Vegetation Ecology, Institute of Botany, Chinese Academy of Sciences, Beijing 100093, China) \\ (2 Graduate School of Chinese Academy of Sciences, Beijing 100039, China)
}

\begin{abstract}
We studied the soil seed bank of a Stipa krylovii steppe community at two sites with different landuse histories: an enclosed pasture, which has been fenced since 2001, and a grazed pasture, which has been continuously grazed for more than 20 years. The experiment was carried out in Duolun County of Xilingol League, Inner Mongolia.

Sixteen $12 \mathrm{~cm}$ diameter soil cores were collected to a depth of $5 \mathrm{~cm}$ at each site on March 30 and 31, 2004. The soil seed bank was estimated by monitoring seedling emergence, a convenient way to compare soils under similar conditions. Vegetation composition was assessed at each site on May and August 2004 by recording the species presented in sixteen $0.5 \mathrm{~m} \times 0.5 \mathrm{~m}$ quadrats that were distributed randomly alongside the seed bank sampling points.
\end{abstract}

A total of 1593 seedlings belonging to 19 species germinated from 32 soil samples. The total seed bank flora at the two sites included 6 grass species and 13 forbs, 18 of which were perennials and 1 annual, 10 monocotyledons and 9 dicotyledons. In the fenced pasture, there were 16 perennials, 6 grasses and 9 monocotyledons from a total of 16 species in the seed bank, whereas 12 perennials, 4 grasses and 5 monocotyledons from a total of 13 species were found in the seed bank of the grazed pasture. The average number of viable seeds per square meter was significantly higher at the fenced site A ( ( $5139 \pm 1848)$ seeds $\left.\mathrm{m}^{-2}\right)$ than that at the grazed site B $\left((3664 \pm 1087)\right.$ seeds $\left.\bullet^{-2}\right)$. Sorensen's similarity index was 0.7111 for the fenced site and 0.6111 for the grazed site. In total, only fifteen species were found in the established vegetation at both sites. As many as $81.0 \%$ of the seeds recorded belonged to only five species (Artemisia frigida, S. krylovi$i$, Potentilla acaulis, Cleistogenes squarrosa, and Allium bidentatum). Another 5 species accounted for $16.2 \%$ of the seeds recorded and the other 9 species accounted for only $2.8 \%$ of the total. 
Our results showed that the scarcity of seeds of some important steppe species combined with the unbalanced distribution of seeds among species may inhibit the restoration process of the $S$. krylovii steppe. Therefore, reseeding and other management steps should be used to speed up the restoration process of the degraded S. krylovii steppe.

Key words Agro-pastoral ecotone, Degraded pasture, Restoration, Similarity

土壤种子库是植被动态的重要制约因素, 影响 着生态系统的抗干扰能力和恢复能力 ( Pugnaire \& Lázaro，2000）。对土壤种子库的认识是全面理解植 被生态学特征的关键所在（Tracy \& Sanderson, 2000）。土壤中种子的存在对于植物物种和群落的 恢复与保护具有重要的应用价值( Akinola et al., 1998)。如果土地管理者想从当前的土壤种子库来 提高希望得到的物种的比例, 那么测定土壤种子库 的组成就是首要的任务 (Tracy \& Sanderson, 2000)。

我国北方农牧交错区是由草地/森林开垦后形 成的一个广阔区域, 总面积约 $800000 \mathrm{~km}^{2}$ (杨晶等, 2004）。近年来, 由于过度放牧和不合理的农业开 垦, 退化草原的面积迅速增加。克氏针茅 (Stipa krylovii) 草原是广泛分布于该地区的植被类型。它 能够适应干旱的生态环境, 具有耐牲畜践踏的特点, 是重要的天然牧场 (刘钟龄和刘书润, 1994)。为了 阻止退化的加剧, 并恢复已经退化的草原, 有必要对 克氏针茅草原开展恢复生态学的研究。土壤种子库 是正在恢复中群落的重要的种子来源 (Kalamees \& Zobel, 1998)。Bai 等(2004)研究了该区域一个移动 沙丘上沙蓬 (Agriophyllum squarrosum) 群落的土壤种 子库, 而对于该地区典型植被克氏针茅草原的土壤 种子库的研究却未见报道。

围栏封育是目前该地区大面积恢复退化天然草 原常用的最有效、最经济的措施。因此我们开展了 围封和放牧条件下克氏针茅草原土壤种子库特征与 差异的比较研究, 分析了地上植被与土壤种子库之 间的关系，以及土壤种子库在植被恢复中的潜在价 值, 旨在为退化克氏针茅草原植被恢复、群落演替的 动态预测和持续利用提供一定的理论依据。

\section{1 研究地点与方法}

\section{1 样地概况}

试验在中国科学院植物研究所多伦恢复生态学 试验示范研究站的十三里滩试验样地内进行。该样 地位于内蒙古自治区锡林郭勒盟南部的多伦县境 内, 地理坐标为 $41^{\circ} 46^{\prime} \sim 42^{\circ} 36^{\prime} \mathrm{N} ; 115^{\circ} 51^{\prime} \sim$ $116^{\circ} 54^{\prime} \mathrm{E}$, 属于温带半干旱大陆性季风气候。年均 降雨量为 $385.5 \mathrm{~mm}$, 多集中在 $6 \sim 8$ 月, 约占全年降
雨量的 $67 \%$, 蒸发量为 $1748 \mathrm{~mm}$ 。年平均气温为 1.6 ${ }^{\circ} \mathrm{C}, \geqslant 10{ }^{\circ} \mathrm{C}$ 积温为 $1917.5{ }^{\circ} \mathrm{C}$ 。无霜期 $100 \mathrm{~d}$ 左右。

该试验样地地势平坦, 植被组成均匀, 地带性土 壤为砾石质栗钙土。在本试验中我们选择了 2 块相 邻样地进行研究。样地 A 为 2001 年围封的克氏针 茅草原, 在此之前为放牧区, 围栏后自然恢复。群落 的建群种为克氏针茅, 优势植物有冷蒿 (Artemisia frigida)、糙隐子草( Cleistogenes squarrosa) 和冰草 ( $A$ gropyron cristatum) 等。样地 $\mathrm{B}$ 在样地 $\mathrm{A}$ 的围栏外, 为 连续的自然放牧区。建群种为克氏针茅, 优势植物 有冷蒿、黄囊苔草( Carex korshinskyi) 和糙隐子草等。

\section{2 土壤种子库调查}

土壤种子库的取样在种子萌发前的早春进行, 时间是 2004 年 3 月 30 和 31 日。在每个样地随机选 取 $30 \mathrm{~m} \times 80 \mathrm{~m}$ 的区域, 在每个区域各布置 2 条间隔 $10 \mathrm{~m}$ 的样线, 在样线上每间隔 $10 \mathrm{~m}$ 为一取样点。在 每个取样点用环刀取直径为 $12 \mathrm{~cm}$, 高为 $5 \mathrm{~cm}$ 的原 状土壤, 连同调落物带回室内。

试验中我们采用幼苗萌发法来测定土壤种子 库, 这对于比较相似土壤条件下的种子库是一种较 为便利的方法 (Pugnaire \& Lázaro, 2000)。取回的土 样在室内先去除大的砾石、调落物和粗根系, 然后均 匀铺在萌发用的花盆内 (约 $3 \mathrm{~cm}$ 厚), 花盆底部预先 填上 $5 \mathrm{~cm}$ 厚的无种子细砂。我们用 3 个填满无种 子细砂的花盆作为对照来监测是否有由空中传播的 种子污染萌发装置。无种子细砂是将细砂置于恒温 $150{ }^{\circ} \mathrm{C}$ 的鼓风干燥箱内烘 $4 \mathrm{~h}$ 后得到的。所有的萌 发装置均摆放在自然光条件下的玻璃室内 (温度 12 $\sim 22{ }^{\circ} \mathrm{C}$ ), 每天浇水 $1 \sim 2$ 次以保持土壤湿润。

待可以辨别出幼苗时分别记录各个样品中的幼 苗数, 部分难以鉴定的幼苗移栽到另外的花盆, 让其 充分生长到可以识别为止。为促进种子的萌发, 每 半个月翻动 1 次土样。直到连续 6 周无新幼苗出 现, 方可认为土壤中的种子已经萌发完全。

\section{3 植被调查}

植被调查分 2 次进行, 第一次是在 2004 年 5 月 30 日, 此时草原植物处于返青后的营养生长期, 第 二次是在 8 月 4 日, 此时是草原植物结实期。在每 个土壤种子库的取样点周围随机布置一个 $0.5 \mathrm{~m} \times$ 
$0.5 \mathrm{~m}$ 的样方, 统计其中种子植物的种类与数目。

\section{4 数据处理}

土壤种子库与地上植被的相似性用 Sorensen 指 数 (Magurran, 1988) 计算:

$$
C C=2(c) /(s 1+s 2)
$$

其中, $C C$ 是 Sorensen 指数的值; $c$ 是在植被与 土壤种子库中都出现的物种数目; $s 1$ 和 $s 2$ 分别对 应于植被和土壤种子库中出现的物种数目。

应用 SPSS 10.0 进行统计分析, 同时对数据进 行了 ANOVA 分析。

\section{2 结果与分析}

\section{1 土壤种子库的物种组成}

在装有无种子细砂的对照花盆里没有幼苗出 现, 表明没有空中传播的种子污染萌发装置。样地 $\mathrm{A}$ (围封样地)和样地 $\mathrm{B}$ (放牧样地) 种子库的物种组 成见表 1 。

多年生植物在样地 A 中所占的比例是 $100 \%$ ， 略高于样地 B 的 $92 \%$; 禾草在样地 $\mathrm{A}$ 和样地 B 中所 占的比例分别是 $37.5 \%$ (6 种)和 $30.8 \%$ (4 种), 后 者略低; 单子叶植物在样地 $\mathrm{A}$ 中所占的比例是 $56.3 \%$, 远高于样地 B 的 $38.5 \%$ 。

\section{2 土壤种子库的数量特征}

在样地 $\mathrm{A}$ 的 16 个土样里萌发了 930 株幼苗, 单 个土样中萌发的幼苗数最多有 114 株, 最少有 25 株, 平均值为 58 株; 样地 B 的 16 个土样里萌发了 663 株幼苗, 单个土样中萌发的幼苗数最多有 57
株, 最少有 18 株, 平均值为 41 株。样地 $\mathrm{A}$ 土壤种子 库的密度是 $(5139 \pm 1848)$ 粒 $\cdot \mathrm{m}^{-2}$, 样地 $\mathrm{B}$ 土壤种子 库的密度是 (3 $664 \pm 1087)$ 粒 $\cdot \mathrm{m}^{-2}$ (表 2), 两者差异 达到了显著性水平 $(F=7.574, p<0.05)$ 。

试验中幼苗萌发的详细情况由表 3 列出。优势 种为冷蒿和克氏针茅, 两者合计占土壤种子库的 $53.9 \%$, 次优势种为星毛委陵菜 (Potentilla acaulis)、 粘隐子草和砂非 (Allium bidentatum), 三者合计占土 壤种子库的 $27.1 \%$ 。二裂委陵菜 $(P$. bifurca) 、菊叶 委陵菜 $(P$. tanacetifolia $) 、$ 猪毛蒿 $(A$. scoparia $) 、$ 冰草 和羊草 (Leymus chinensis) 这 5 种常见植物的种子数 占土壤种子库的 $16.2 \%$, 其余 9 种植物的种子数仅 占土壤种子库的 $2.8 \%$ 。豆科植物 2 种, 扁蓄豆 (Melilotoides ruthenica) 和白花黄芪 (Astragalus galactites) 分别有 1 粒和 8 粒种子, 合计占土壤种子库的 $0.6 \%$ 。两种重要的多年生禾草: 克氏针茅和粘隐子 草在样地 $\mathrm{A}$ 的种子数分别为 154 粒和 22 粒, 显著小 于在样地 B 中的 180 粒和 138 粒, 而草原退化的指 示植物冷蒿在样地 $\mathrm{A}$ 的种子数(334 粒) 显著大于在 样地 B 中的种子数 ( 190 粒)。

\section{3 土壤种子库与地上植被的相似性}

在地上植被中记录了 34 个物种, 样地 A 有 29 种, 其土壤种子库与地上植被共有物种数 16 ; 样地 $\mathrm{B}$ 有 23 种, 其土壤种子库与地上植被共有物种数 11 (表 2)。采用 Sorensen 指数计算土壤种子库与地上 植被的相似性, 样地 $\mathrm{A}$ 是 0.711 , 样地 $\mathrm{B}$ 是 0.6111 。

表 $\mathbf{1}$ 样地 $\mathbf{A}$ 和样地 $\mathbf{B}$ 中土壤种子库的物种组成

Table 1 Total numbers of species in the seed bank of site A and site B

\begin{tabular}{|c|c|c|c|c|c|c|c|}
\hline $\begin{array}{l}\text { 地点 } \\
\text { Site }\end{array}$ & $\begin{array}{c}\text { 物种数目 } \\
\text { Number of species }\end{array}$ & $\begin{array}{l}\text { 禾草 } \\
\text { Grasses }\end{array}$ & $\begin{array}{l}\text { 非禾草 } \\
\text { Forbs }\end{array}$ & $\begin{array}{c}\text { 一年生植物 } \\
\text { Annuals }\end{array}$ & $\begin{array}{c}\text { 多年生植物 } \\
\text { Perennials }\end{array}$ & $\begin{array}{c}\text { 单子叶植物 } \\
\text { Monocotyledons }\end{array}$ & $\begin{array}{l}\text { 双子叶植物 } \\
\text { Dicotyledons }\end{array}$ \\
\hline A & 16 & 6 & 10 & 0 & 16 & 9 & 7 \\
\hline B & 13 & 4 & 9 & 1 & 12 & 5 & 8 \\
\hline
\end{tabular}

表 2 样地 $\mathbf{A}$ 和样地 $\mathbf{B}$ 土壤种子库的密度 (平均值 \pm 标准误差)

Table 2 Density of the soil seed bank of site A and site B (Mean $\pm S E)$

\begin{tabular}{cccccccc}
\hline & \multicolumn{6}{c}{ 土壤种子库的密度 $\left(\right.$ 粒 $\left.\cdot \mathrm{m}^{-2}\right)$ Density of the soil seed bank $\left(\right.$ seeds $\left.\bullet \mathrm{m}^{-2}\right)$} \\
\cline { 2 - 7 } \begin{tabular}{c} 
Sites \\
\cline { 2 - 7 }
\end{tabular} & $\begin{array}{c}\text { 禾草 } \\
\text { Grasses }\end{array}$ & $\begin{array}{c}\text { 非禾草 } \\
\text { Forbs }\end{array}$ & $\begin{array}{c}\text { 一年生植物 } \\
\text { Annuals }\end{array}$ & $\begin{array}{c}\text { 多年生植物 } \\
\text { Perennials }\end{array}$ & $\begin{array}{c}\text { 单子叶植物 } \\
\text { Monocotyledons }\end{array}$ & $\begin{array}{c}\text { 双子叶植物 } \\
\text { Dicotyledons }\end{array}$ & $\begin{array}{c}\text { 合计 } \\
\text { Total }\end{array}$ \\
\hline A & $1647 \pm 872$ & $3493 \pm 1487$ & 0 & $5139 \pm 1848$ & $2310 \pm 1041$ & $2829 \pm 1489$ & $5139 \pm 1848$ \\
B & $1840 \pm 601$ & $1824 \pm 896$ & $11 \pm 30$ & $3653 \pm 1098$ & $1857 \pm 597$ & $1807 \pm 905$ & $3664 \pm 1087$ \\
\hline
\end{tabular}


表 3 土壤种子库与植被中物种的存在情况

Table 3 Occurrence of species in the soil seed bank and vegetation

\begin{tabular}{|c|c|c|c|c|c|}
\hline \multirow{2}{*}{$\begin{array}{c}\text { 物种 } \\
\text { Species }\end{array}$} & \multicolumn{3}{|c|}{ 各样地的种子数目 (粒) Seed number of each site (seeds) } & \multicolumn{2}{|c|}{ 植被 Vegetation } \\
\hline & $\mathrm{A}$ & $\mathrm{B}$ & 合计 Sum & A & B \\
\hline 灰绿藜 Chenopodium glaucum & 0 & 2 & 2 & + & - \\
\hline 星毛委陵菜 Potentilla acaulis & 111 & 55 & 166 & + & - \\
\hline 二裂委陵菜 Potentilla bifurca & 1 & 23 & 24 & + & + \\
\hline 菊叶委陵菜 Potentilla tanacetifolia & 15 & 8 & 23 & + & + \\
\hline 扁蓄豆 Melilotoides ruthenica & 0 & 1 & 1 & + & + \\
\hline 白花黄花 Astragalus galactites & 7 & 1 & 8 & + & + \\
\hline 冷蒿 Artemisia frigida & 334 & 190 & 524 & + & + \\
\hline 猪毛蒿 Artemisia scoparia & 41 & 47 & 88 & + & + \\
\hline 阿尔泰狗娃花 Heteropappus altaicus & 3 & 0 & 3 & + & + \\
\hline 黄囊苔草 Carex korshinskyi & 10 & 0 & 10 & + & + \\
\hline 细叶早熟禾 Poa angustifolia & 4 & 0 & 4 & + & + \\
\hline 克氏针茅 Stipa krylovii & 154 & 180 & 334 & + & + \\
\hline 冰草 Agropyron cristatum & 53 & 9 & 62 & + & + \\
\hline 羊草 Leymus chinensis & 55 & 6 & 61 & + & + \\
\hline 粘隐子草 Cleistogenes squarrosa & 22 & 138 & 160 & + & + \\
\hline 砂非 Allium bidentatum & 106 & 0 & 106 & + & + \\
\hline 细叶非 Allium tenuissimum & 3 & 0 & 3 & + & + \\
\hline 长梗非 Allium neriniflorum & 11 & 0 & 11 & + & - \\
\hline 野非 Allium ramosum & 0 & 3 & 3 & + & + \\
\hline 瓣荵唐松草 Thalictrum petaloideum & 0 & 0 & 0 & + & - \\
\hline 石竹 Dianthus chinensis & 0 & 0 & 0 & + & - \\
\hline 刺㢣 Chenopodium aristatum & 0 & 0 & 0 & - & + \\
\hline 绢毛委陵菜 Potentilla sericea & 0 & 0 & 0 & + & + \\
\hline 长毛荚黄芪 Astragalus monophyllus & 0 & 0 & 0 & + & - \\
\hline 鳞叶龙胆 Gentiana squarrosa & 0 & 0 & 0 & + & - \\
\hline 糙苏 Phlomis umbrosa & 0 & 0 & 0 & + & + \\
\hline 达乌里芯芭 Cymbaria dahurica & 0 & 0 & 0 & + & - \\
\hline 绢毛蒿 Artemisia sericea & 0 & 0 & 0 & - & + \\
\hline 蒲公英 Taraxacum mongolicum & 0 & 0 & 0 & - & + \\
\hline 鸦葱 Scorzonera austriaca & 0 & 0 & 0 & + & - \\
\hline 狭叶山苦卖 Ixeris chinensis & 0 & 0 & 0 & - & + \\
\hline 少花顶冰花 Gagea pauciflora & 0 & 0 & 0 & + & - \\
\hline 细叶感尾 Iris tenuifolia & 0 & 0 & 0 & + & - \\
\hline 马萄 Iris lactea & 0 & 0 & 0 & - & + \\
\hline 合计 Total & 930 & 663 & 1593 & & \\
\hline
\end{tabular}

每样地 16 个土样中萌发的幼苗数都计算在内 Total number of germinated seedlings of the 16 soil samples of each site was calculated + : 表示该物 种在相应地点的植被中出现 Denotes species which occurred in the vegetation - : 表示该物种在相应地点的植被中不存在 Denotes species which did not occurred in the vegetation

\section{3 讨 论}

本研究中克氏针茅草原土壤种子库的密度大小 为 $(3664 \pm 1087)$ 和 $(5139 \pm 1848)$ 粒 $\cdot \mathrm{m}^{-2}$, 与同处 于农牧交错带的科尔沁沙地围封草地的种子库密度 （3 $314 \pm 739 ）$ 粒 $\cdot \mathrm{m}^{-2}($ 赵文智和白四明, 2001) 和内 蒙古中部冷蒿草原的种子库密度 $1125 \sim 7625$ 粒・ $\mathrm{m}^{-2}$ (苏德毕力格等, 2000 ) 处于同一水平; 土壤 种子库中的物种数为 19 种, 与冷蒿草原的 18 种接 近,略低于科尔沈围封草地的 25 种。

一些关于草原土壤种子库的研究中, 地上植被
的物种多样性调查多选在生长旺季的 7 或 8 月份进 行 ( O' Connor \& Pickett, 1992; Pugnaire \& Lázaro, 2000), 而早春植物一般到 6 月份就能够完成生活 史, 在 7 月及以后的调查会将它遗漏, 由此得到的物 种多样性偏低。我们在 5 月份的植被调查中, 发现 1 种早春植物少花顶冰花 (Gagea pauciflora), 而在 8 月份的植被调查中已经找不到该物种, 因此我们认 为在统计地上植被的物种多样性时, 5 月份的调查 是有必要的。

许多文章都研究了土壤种子库与地上植被之间 的相似性, 但是不同的作者所指的相似性标准并不 
统一( Jutila, 1998)。一些作者使用 Simpson 指数或 者 Sorensen 指数 (Levassor et al., 1990; Navie et al., 1996), 还有一些作者仅仅列出两者之间共同的物种 数目 (Wisheu \& Keddy, 1991)。本文中我们采用了 Sorensen 指数来计算地上植被与土壤种子库的相似 性。许多研究认为土壤种子库与地上植被的相似性 很低 (Douglas, 1965; Johnston et al., 1969; Rabinowitz, 1981; Hassan \& West, 1986; Bertiller, 1992; Jutila，1998）。本文所研究的围封与放牧条件下克 氏针茅草原土壤种子库与地上植被的相似性较高, 这个结果与 Tracy 和 Sanderson(2000)在美国东北部 放牧草地的研究结果一致。

克氏针茅草原中放牧样地的种子库密度显著低 于围封样地, 支持放牧能够降低土壤种子库的密度 (Bertiller, 1992; Russi et al., 1992; McDonald et al ., 1996)的观点。经过 3 年的围栏封育, 克氏针茅草原 围栏内的植被明显比围栏外的植被具有更大的密度 和高度, 能够积聚更多的包含种子的调落物 ( Andresen et al., 1990; Jutila，1997), 因此具有较大的 土壤种子库。Kinucan 和 Smeins (1992) 指出放牧能 够增加土壤种子库中一年生双子叶植物的比重, 在 我们的围封样地种子库中没有发现一年生植物, 而 在放牧样地中有 1 种一年生植物灰绿藜 (Chenopodium glaucum) 出现, 双子叶植物在种子库中占各自物 种数的比例却是放牧样地远高于围封样地, 说明放 牧能够增加双子叶植物的比重。

两种重要的多年生禾草: 克氏针茅和糙隐子草 在放牧样地的种子库密度显著大于在围封样地中的 密度, 表明多年生禾草在围封条件下可能比在放牧 条件下更倾向于无性繁殖。在放牧条件下,牲畜啃 食、践踏等环境胁迫增强了自然选择的压力, 在高的 选择压力下, 多年生禾草倾向于能够产生更多变异 的有性生殖方式来适应环境胁迫; 在围封条件下,环 境相对稳定, 自然选择的压力小, 多年生禾草倾向于 保持原有基因型不变, 因而更多地采用无性繁殖方 式来延续种群。冷蒿是草原退化的指示植物, 它在 围封草原土壤种子库中的密度增加可能是由两方面 的原因造成的:一是围封后的生境不适合冷蒿种子 的萌发, 以至积累了较多的种子;二是围封后植被的 恢复给冷高的生长增强了选择压力, 因而产生了更 多的种子。

在地上植被的 34 个物种中仅有 19 个物种出现 在土壤种子库中 (表 3), 由于土壤种子库中一些重 要物种的缺失和极不均匀的分布, 很可能降低退化
的克氏针茅草原的恢复速度。因此, 草原的管理者 们应该考虑采取补播这些重要物种并结合其它的一 些恢复措施来加快退化克氏针茅草原的恢复进程。

\section{参 考 文 献}

Akinola MO, Thompson K, Buckland SM (1998). Soil seed bank of an upland calcareous grassland after 6 years of climate and management manipulations. Journal of Applied Ecology, 35,544 -552 .

Andresen H, Bakker JP, Brongers M, Heydemann B, Irmler U (1990) . Long-term changes of salt marsh communities by cattle grazing. Vegetatio, 89,137-148.

Bai WM, Bao XM, Li LH (2004). Effects of Agriophyllum squarrosum seed banks on its colonization in a moving sand dune in Hunshandake Sand Land of China. Journal of Arid Environments, $59,151-157$.

Bertiller MB (1992). Seasonal variation in the seed bank of a Patagonian grassland in relation to grazing and topography. Journal of Vegetation Science, 3,47-54.

Douglas G (1965). The weed flora of chemically-renewed lowland swards. Journal of British Grassland Society, 4,189-194.

Hassan MA, West NE (1986). Dynamics of soil seed pools in burned and unburned sagebrush semi-deserts. Ecology, 67,269 -272 .

Johnston A, Smoliak S, Stringer PW (1969). Viable seed population in Alberta prairie top soils. Canadian Journal of Plant Science, $49,75-82$.

Jutila HM (1997) . Vascular plant species richness in grazed and ungrazed coastal meadows, SW Finland. Annales Botanici Fennici, 34,200-219.

Jutila HM (1998). Seed banks of grazed and ungrazed Baltic seashore meadows. Journal of Vegetation Science, 9,395-408.

Kalamees R, Zobel M (1998). Soil seed bank composition in different successional stages of a species rich wooded meadow in Laelatu, western Estonia. Acta Oecologica, 19,175 - 180 .

Kinucan RJ, Smeins FE (1992). Soil seed bank of a semiarid Texas grassland under 3 long-term (36-years) grazing regimes. American Midland Naturalist, 128,11-21.

Levassor C, Ortega M, Peco B (1990). Seed bank dynamics of Mediterranean pastures subjected to mechanical disturbance. Journal of Vegetation Science, 1,339- 344 .

Liu ZL(刘钟龄), Liu SR (刘书润)（1994）。Flora Intramongoli$c a$ (内蒙古植物志) Tomus 5. Typis Intramongolicae Popularis, Huhhot, 199. (in Chinese)

Magurran AE (1988). Ecological Diversity and its Measurement. Princeton University Press. Princeton, New Jersey.

McDonald AW, Bakker JP, Vegelin K (1996). Seed bank classification and its importance for the restoration of species-rich floodmeadows. Journal of Vegetation Science, 7,156-164.

Navie SC, Cowley RA, Rogers RW (1996). The relationship between distance from water and the soil seed bank in a grazed se- 
mi-arid subtropical rangeland. Australian Journal of Botany, 44, $421-431$.

O' Connor TG, Pickett GA (1992). The influence of grazing on seed production and seed banks of some African savanna grasslands. Journal of Applied Ecology, 29,247 - 260 .

Pugnaire FI, Lázaro R (2000). Seed bank and understorey species composition in a semi-arid environment: the effect of shrub age and rainfall. Annals of Botany, 86,807-813.

Rabinowitz D (1981) . Buried viable seeds in a North American tallgrass prairie: the resemblance of their abundance and composition to dispersing seeds. Oikos, 36,191-195.

Russi L, Cocks PS, Roberts EH (1992). Seed bank dynamics in a Mediterranean grassland. Journal of Applied Ecology, 29,763771 .

Sudebilige H(苏德毕力格), Li YH(李永宏), Yong SP(雍世 鹏), Sa R (萨仁) (2000). Germinable soil seed bank of Artemisia frigida grassland and its response to grazing. Acta Eco- logica Sinica (生态学报),20,43-48.

Tracy BF, Sanderson MA (2000). Seedbank diversity in grazing lands of the Northeast United States. Journal of Range Management, 53,114- 118 .

Wisheu IC, Keddy PA (1991). Seed banks of a rare wetland plant community: distribution patterns and effects of human-induced disturbance. Journal of Vegetation Science, 2,181-188.

Yang J(杨晶), Huang JH(黄建辉), Zhan XM(詹学明), Li X (李金金), Du LH(杜丽华), Li LH(李凌浩) (2004). The diurnal dynamic patterns of soil respiration for different plant communities in the Agro-Pastoral Ecotone with reference to different measuring methods. Acta Phytoecologica Sinica (植物生态学 报),28,318-325. (in Chinese with English abstract)

Zhao WZ(赵文智), Bai SM(白四明) (2001). Characteristics of seed bank at fenced grassland in Horqin Sandy Land. Journal of Desert Research (中国沙漠) , 21, 204 - 208. (in Chinese with English abstract) 